$\underline{\text { Artikel Penelitian }}$

\title{
PENGUKURAN KINERJA DENGAN PENDEKATAN BALANCED SCORECARD DI INSTALASI GAWAT DARURAT RSUD Dr. M. HAULUSSY AMBON
}

\author{
Faysal Kastella ${ }^{1}$, Fridawaty Rivai ${ }^{2}$, Suriah $^{3}$ \\ IProgram Studi Kesehatan Masyarakat \\ ${ }^{2}$ Bagian Manajemen Rumah Sakit, Fakultas Kesehatan Masyarakat, \\ ${ }^{3}$ Bagian Promosi Kesehatan dan Ilmu Perilaku, Fakultas Kesehatan Masyarakat, \\ Universitas Hasanuddin, Makassar \\ Corresponding author e-mail : faysalcasthella@yahoo.co.id
}

\begin{abstract}
Abstrak
Pendahuluan. Balanced scorecard merupakan metode yang dapat mengukur kinerja keberhasilan rumah sakit yang bukan keberhasilan finansial atau untuk mencapai tujuan jangka pendek saja tetapi mempertimbangkan aspek non finansial dan dapat menawarkan pemetaan strategis yang sistimatis dan komprehensif bagi rumah sakit. Tujuan. Penelitian ini bertujuan untuk mendapatkan gambaran kinerja dengan menggunakan pendekatan balanced scorecard di instalasi gawat darurat RSUD Dr. M. Haulussy Ambon. Metode. Penelitian ini menggunakan metode kuantitatif, dengan sampel pelanggan sebanyak 147 responden dan sampel pegawai instalasi gawat darurat sebanyak 36 responden, sedangkan data kualitatif dilakukan dengan wawancara mendalam. Hasil. Hasil penelitian menggambarkan kinerja instalasi gawat darurat dari perspektif pelanggan dalam kondisi kurang sehat dengan total score $62,5 \%$, dari perspektif keuangan dalam kondisi tidak sehat dengan total score $25 \%$, sedangkan perspektif proses bisnis internal dalam kondisi kurang sehat dengan total score $60,7 \%$, serta perspektif pembelajaran dan pertumbuhan dalam kondisi sangat sehat dengan total score $70 \%$, untuk kinerja instalasi gawat darurat secara umum berada dalam kondisi kurang sehat dengan total score 58,02\%, dimana rumah sakit lebih cenderung untuk berfokus pada aspek internal, orang dan non finansial. Kesimpulan. Kinerja instalasi gawat darurat dari perspektif pelanggan berada dalam kondisi kurang sehat, dari perspektif keuangan dalam kondisi tidak sehat, untuk perspektif proses bisnis internal berada dalam kondisi kurang sehat, serta dari perspektif pembelajaran dan pertumbuhan dalam kondisi sangat sehat. Sedangkan kinerja instalasi gawat darurat secara keseluruhan berada dalam kondisi kurang sehat dan belum adanya keseimbangan baik antar perspektif maupun antar aspek-aspek keseimbangan (internal-eksternal, proses-orang dan keuangan-non keuangan).
\end{abstract}

Kata kunci : Kinerja, Balanced Scorecard, Instalasi Gawat Darurat

\section{Abstract}

Introduction. Balanced scorecard is a method that can measure the performance of hospital successes in nonfinancial aspect or to achieve short-term goals by considering non-financial aspects. This can offer a systematic and comprehensive strategic mapping for the hospital. Aims. This study aims to obtain a performance overview by using a balanced scorecard approach at the emergency department of Dr. M. Haulussy Hospital, Ambon. Methods. The research uses quantitative and qualitative methods, the samples consist of 147 costumer respondents and 36 employee respondents from the emergency installation, the qualitative research was conducted using indepth interviews. Result. The results of this study illustrate the performance of emergency installation, from the perspective of customers in unhealthy conditions with a total score of 62.5\%, The performance is also unhealthy from the perspective of financial and internal business process with total scores of $25 \%$ and $60.7 \%$ respectively. However, in terms of learning and growth perspective, the performance is in very healthy condition with a total score of 70\%, in general, it can be considered that the performance of the emergency installation is unhealthy with a total score of $58.02 \%$. The hospitals tend to focus more on the internal aspect, people and financial matter. Conclusion: Emergency installation performance from the perspective of customer, financial and internal business processes being in a poor condition, and from a learning and growth perspective in very good conditions. Overall the performance of the emergency installation is in poor condition and there is no balance between perspective and inter-balance aspects (internal-external, process-person and non-financial).

Key words: Performance, Balanced Scorecard, Installation of Emergency 


\section{Pendahuluan}

Rumah sakit sebagai organisasi nirlaba memiliki peran dalam memberikan pelayanan kesehatan yang professional dan bermutu serta terjangkau semua lapisan masyarakat, serta memberikan pelayanan kesehatan dasar dan pelayanan kesehatan lanjutan sesuai kelas rumah sakit dan standar yang telah ditetapkan, sehingga keberadaan rumah sakit sebagai ujung tombak dalam pembangunan kesehatan. Namun tidak sedikit keluhan yang diarahkan karena kualitas kinerja pelayanan rumah sakit yang dinilai masih rendah. Hal ini dikarenakan masih terbatasnya sumber daya baik sumber daya finansial maupun sumber daya non finansial. ${ }^{1}$

Suatu organisasi agar bisa bersaing dan berkembang perlu dilakukan perbaikan pada setiap kinerja perusahaannya. Hal ini dikarenakan pengukuran kinerja merupakan bagian dari fungsi pengendalian aktivitas manajemen yang dapat diketahui tingkat efisiensi dan efektivitasnya. Dewasa ini, kinerja suatu perusahaan merupakan faktor mutlak yang menentukan eksistensi dan daya saing suatu perusahaan. Makin pentingnya kesadaran tentang kinerja disebabkan karena persaingan bisnis yang semakin tinggi serta peningkatan kesadaran konsumen terhadap kebutuhan dan keinginannya. ${ }^{1}$

Kekritisan konsumen terhadap kinerja perusahaan inilah yang menyebabkan perusahaan harus selalu menjaga kinerjanya dan melakukan peningkatan kinerja secara terus menerus, apabila tidak ingin kehilangan konsumennya. Menurut Anthony (1965) yang 51 dikutip oleh Mahmudi (2015), mengatakan bahwa pengukuran kinerja merupakan elemen penting dalam sistem pengendalian manajemen yang artinya sebagai proses untuk memastikan bahwa sumber daya yang diperoleh dan digunakan secara efektif dan efisien untuk mencapai tujuan organisasi. ${ }^{1}$

Sedangkan menurut Zelman (2003) dalam Nugraha (2012), mengatakan kalau saat ini banyak rumah sakit telah mengadopsi sistem kinerja yang multidimensional untuk mendukung pencapaian tujuan dan misinya. Hal ini disebabkan semakin banyaknya tuntutan maupun kebutuhan masyarakat akan pelayanan kesehatan yang telah mengalami pergeseran yaitu dari Dumb Customer (pelanggan yang sensitif terhadap perubahan harga) menjadi Snop Customer (pelanggan yang sangat sensitif terhadap persepsi kualitas) bahkan karena perubahan-perubahan teknologi, ilmu pengetahuan dan pengembangan budaya kemudian bergeser lagi menjadi Smart Customer dimana pelanggan akan berorientasi pada nilai-nilai / values. Fenomena tersebut terjadi diberbagai jenjang pelayanan kesehatan, khusus untuk rumah sakit, tidak saja keluhankeluhan masyarakat yang merasa kecewa dengan pelayanan rumah sakit, baik dari segi mutu, kemudahan maupun tarif, akan tetapi juga perkembangan zaman, perubahan lingkungan eksternal maupun internal. ${ }^{2,3}$

Kenyataan inilah yang menjadi awal terciptanya suatu konsep untuk merancang sistem pengukuran kinerja yang lebih komprehensif yang disebut dengan balanced http://ojs3.unpatti.ac.id/index.php/moluccamed 
scorecard, yang merupakan metode pengukuran kinerja untuk menyeimbangkan pengukuran aspek keuangan dengan aspek non keuangan dengan memasukkan empat perspektif di dalamnya yaitu perspektif pembelajaran dan pertumbuhan, perspektif proses bisnis internal, perspektif pelanggan serta perspektif keuangan. ${ }^{4}$

Pemanfaatan balanced scorecard sebagai suatu metode pengukuran kinerja lebih banyak digunakan diperusahaan-perusahaan bisnis yang menghasilkan barang, tetapi dapat juga diterapkan pada rumah sakit yang bergerak dalam bidang usaha jasa, sebagai contoh adalah Peel Memorial Hospital Vancouver Canada dan Mayo Clinic di United States. Kedua rumah sakit tersebut telah menggunakan kerangka pengukuran kinerja dan evaluasi serta menerapkannya kedalam perencanaan strategik organisasi untuk meningkatkan kinerjanya. Jhon R. Griffith \& Jhon G. King dalam Journal of Healthcare Management edisi Jan/Feb 2000 dan Chee W. Chow et al dalam jurnal yang sama edisi Mei 1998 menganjurkan balanced scorecard untuk digunakan dalam organisasi kesehatan yaitu rumah sakit. Hal ini didukung oleh beberapa peneliti dari Michigan University telah mampu menentukan validitas, reliabilitas, dan sensitivitas dari metode balanced scorecard yang berorientasi pada pembandingan indikator yang digunakan rumah sakit untuk mengukur kinerjanya dibandingkan dengan kinerja para kompetitornya. Konseptual balanced scorecard tidak hanya mencakup indikator kinerja rumah sakit tetapi juga untuk membantu dalam membandingkan kinerja rumah sakit. Sehingga metode balanced scorecard akan bermanfaat untuk mengidentifikasi kesempatan dalam peningkatan kinerja akibat dari adanya hasil pengukuran kinerja yang nilainya masih rendah. ${ }^{4}$

Instalasi pelayanan pertama bagi pasien yang datang ke rumah sakit adalah rawat jalan dan rawat darurat, namun terkhusus pelayanan kedokteran yang membutuhkan waktu segera, cepat dan profesional untuk menyelamatkan kehidupan adalah instalasi gawat darurat yang menyelenggarakan pelayanan darurat yang berjalan terus menerus selama 24 jam dengan berbagai tingkat kegawatan (Standar pelayanan Minimum RSUD Dr. M. Haulussy Ambon, 2012), serta memiliki tim kerja dengan kemampuan khusus dan peralatan gawat darurat yang terorganisir. ${ }^{5}$

Berkaitan dengan hal tersebut, pemberian pelayanan gawat darurat juga sebagai salah satu layanan yang diberikan di RSUD. Dr. M. Haulussy yang merupakan rumah sakit pemerintah propinsi yang berada di kota Ambon. Sebagai bahan pertimbangan untuk menganalisis kinerja instalasi gawat darurat, peneliti mengambil beberapa data kunjungan tiga tahun terakhir (2013-2015), yaitu terdapat 18.956 kunjungan di tahun 2013, sebanyak 17.789 kunjungan di tahun 2014, dan pada tahun 2015 terdapat 16.002 kunjungan (Profil Rumah Sakit, 2015). Oleh karena itu, untuk menjadikan instalasi gawat darurat sebagai andalan sesuai dengan visi dan misi rumah sakit http://ojs3.unpatti.ac.id/index.php/moluccamed 
(Renstra RSUD Dr. M. Haulussy Ambon, 2014). Diperlukan kinerja rumah sakit yang baik, yang akan menuntun pada suatu kerangka kerja yang stretegis, tepat dan dapat memicu keunggulan berkompetisi secara sehat di era globalisasi ini. ${ }^{6}$

Dengan demikian dalam penelitian ini, balanced scorecard yang merupakan sebuah pendekatan atau alat standar yang dipilih peneliti, karena metode ini dapat mengukur kinerja keberhasilan suatu rumah sakit bukan dengan keberhasilan finansial saja, atau membawa organisasi kearah jangka pendek tetapi juga dengan mempertimbangkan aspek non finansial, yang dapat menawarkan pemetaan strategi yang sistimatis dan komprehensif bagi rumah sakit untuk menerjemahkan visi dan misi kedalam sekumpulan ukuran kinerja yang saling berkaita $^{7}$, dan ukuran-ukuran ini tidak hanya digunakan untuk mengendalikan perilaku tetapi untuk dapat mengartikulasikan strategi rumah sakit dan membantu menyesuaikan inisiatif individu, dan lintas unit demi tercapainya sasaran bersama, dan dapat memberikan gambaran kinerja instalasi gawat darurat RSUD. Dr. M. Haulussy Ambon yang merupakan salah satu unit kerja yang bersifat operasional (Micro).

\section{Metode}

Penelitian ini dilaksanakan di instalasi gawat darurat RSUD Dr. M. Haulussy Ambon dari Januari hingga Maret 2017. Metode penelitian ini adalah metode kuantitatif dengan pendekatan balanced scorecard, yang menggunakan data primer dan sekunder untuk mengukur kinerja berdasarkan empat perspektif balanced scorecard. ${ }^{8}$ Populasi penelitian adalah seluruh pegawai yang bertugas di instalasi gawat darurat, dan pasien atau keluarganya yang mendapat pelayanan gawat darurat selama periode penelitian. Penarikan sampel dalam penelitian ini menggunakan teknik Purposive sampling dengan besar sampel untuk pasien/keluarganya sebanyak 147 responden dan untuk pegawai 36 responden.

Data yang dikumpulkan pada penelitian adalah data primer dan data sekunder. Data primer diambil melalui penyebaran kuesioner, sedangkan data sekunder melalui telaah/penelusuran dokumen yang diperoleh dari bagian terkait seperti: profil rumah sakit, profil instalasi gawat darurat, RM, data keuangan, data diklit dll. Sedangkan untuk kualitatif melalui wawancara mendalam terhadap pegawai instalasi gawat darurat. Analisa yang digunakan untuk data kuantitatif dilakukan dengan pemberian nilai dan bobot pada data yang berkaitan dengan variabel pengukuran yang kemudian di skoring sesuai standar kriteria balanced sciorecard dan disajikan dalam bentuk tabel dan disertai narasi, sedangkan data kualitatif dari hasil wawancara mendalam disajikan dalam bentuk content analysis. $^{8}$

http://ojs3.unpatti.ac.id/index.php/moluccamed 


\section{Hasil}

\section{Perspektif Pelanggan (Customer)}

Penilaian kinerja IGD dari perspektif pelanggan adalah melalui kuesioner kepuasan pelanggan yang terdiri dari beberapa indikator, yaitu ; kemudahan mencapai IGD, kepuasan pelayanan dokter, kepuasan pelayanan perawat dan waktu tunggu untuk rawat inap, sedangkan untuk perhitungan pertumbuhan kunjungan pelanggan digunakan data jumlah kunjungan IGD pada tahun 2014 s/d 2016.

Tabel 1 menunjukkan bahwa kinerja instalasi gawat darurat RSUD Dr. M. Haulussy Ambon dari perspektif pelanggan (costumer) sesuai dengan kriteria standar balanced scorecard barada pada kisaran $50<\mathrm{TS}<65$ dengan total skor $62,5 \%$, yang termasuk dalam kondisi kurang sehat dengan kategori BBB.

\section{Perspektif Keuangan (Finansial)}

Kinerja keuangan IGD RSUD. Dr. M. Haulussy Ambon, terdiri dari beberapa indikator penelitian, antara lain ; tingkat pertumbuhan pendapatan IGD, tingkat pertumbuhan pengeluaran IGD, perbandinagn realisasi dan rencana pendapatan IGD serta perbandingan pendapatan dan pengeluaran IGD

Tabel 1 menunjukkan bahwa kinerja instalasi gawat darurat RSUD Dr. M. Haulussy Ambon dari perspektif keuangan (financial) sesuai dengan kriteria standar balanced scorecard barada pada kisaran $20<\mathrm{TS}<30$ dengan total skor $25 \%$, yang termasuk dalam kondisi tidak sehat dengan kategori CCC.
Tabel 1. Nilai kriteria standar masing masing perspektif \& kinerja di IGD RSUD. Dr. M. Haulussy Ambon - Tahun 2017

\begin{tabular}{lcccc}
\hline \multicolumn{1}{c}{ Perspektif } & $\begin{array}{c}\text { Nilai Akhir } \\
\text { Komponen } \\
(\%)\end{array}$ & Total Skor & Kondisi & $\begin{array}{c}\text { Kateg } \\
\text { ori }\end{array}$ \\
\hline Pelanggan & $62,5 \%$ & $50<T S<65$ & Kurang & BBB \\
Keuangan & $25 \%$ & $20<T S<30$ & Sehat & CCC \\
$\begin{array}{l}\text { Proses Bisnis } \\
\text { Internal }\end{array}$ & $60,7 \%$ & $50<T S<65$ & Tidak Sehat & BBB \\
$\begin{array}{l}\text { Pembelajaran } \\
\text { dan } \\
\text { pertumbuhan }\end{array}$ & $70 \%$ & $65<T S<80$ & Kurang & \\
& & & Sehat & A \\
& & & Sangat & \\
\hline Kinerja IGD & $58,02 \%$ & $50<T S<65$ & Kurang & Behat \\
\hline
\end{tabular}

Perspektif Proses Bisnis Internal (Internal Bussiness Process)

Penilaian kinerja IGD dari perspektif proses bisnis internal adalah dengan menjabarkan indikator dalam standar pelayanan minimal (SPM) rumah sakit sesuai dengan Kepmenkes RI Nomor : 129/Menkes/SK/II/2008, yang terdiri dari ; kemampuan menangani life saving anak dan dewasa, jam buka pelayanan gawat darurat, pemberi pelayanan gawat darurat yang bersertifikat, ketersediaan tim penanggulangan bencana, waktu tanggap dokter di gawat darurat, kematian pasien di IGD ( $<24$ jam) dan tidak adanya pasein yang diharuskan membayar uang muka.

Tabel 1 menunjukkan bahwa kinerja instalasi gawat darurat RSUD Dr. M. Haulussy Ambon dari perspektif proses bisnis internal (internal business process) sesuai dengan 
kriteria standar balanced scorecard barada pada kisaran $50<\mathrm{TS}<65$ dengan total skor $60,7 \%$, yang termasuk dalam kondisi kurang sehat dengan kategori BBB.

Perspektif Pembelajaran dan Pertumbuhan (Learn \& Growth)

Penilaian kinerja IGD dari perspektif pembelajaran dan pertumbuhan adalah melalui kuesioner 1) kepuasan pegawai yang terdiri dari; kepuasan terhadap gaji, kepuasan terhadap promosi, kepuasan terhadap teman kerja, kepuasan terhadap atasan dan kepuasan terhadap pekerjaan sendiri, sedangkan untuk kondisi 2) retensi pegawai, 3) tingkat absensi pegawai, 4) produktivitas pegawai serta 5) akses pelatihan dan pendidikan, yang dilakukan melalui penelusuran dokumen dari data di bagian kepegawaian, keuangan dan diklat rumah sakit.

Tabel 1 menunjukkan bahwa kinerja instalasi gawat darurat RSUD Dr. M. Haulussy Ambon dari perspektif pembelajaran dan pertumbuhan (learning \& growth) sesuai dengan kriteria standar balanced scorecard barada pada kisaran $65<\mathrm{TS}<80$ dengan total skor $70 \%$, yang termasuk dalam kondisi sangat sehat dengan kategori A. Hasil wawancara mendalam terkait sistem dan triage di IGD belum berjalan baik, masih kurangnya petugas serta fasilitas dan sarana prasarana life saving dan lainnya masih terbatas dan belum memadai. Sistem reward dan punishment juga tidak diterapkan dengan baik, dengan beban kerja yang tinggi dan kompleks, serta tidak adanya 55 program peningkatan kualitas SDM yang terencana dan berkesinambungan, namun terkait sikap sesama petugas di IGD memiliki kerjasama yang baik dalam pelaksanaan tugas.

Kinerja secara keseluruhan berdasarkan skoring balanced scorecard di instalasi gawat darurat RSUD Dr. M. Haulussy Ambon

Tabel 1 menunjukkan bahwa kinerja instalasi gawat darurat RSUD Dr. M. Haulussy Ambon secara keseluruhan berada pada kisaran $50<\mathrm{TS}<65$ dengan total skor $58,02 \%$, yang termasuk dalam kondisi kurang sehat dengan kategori BBB.

Namun sesuai pada tabel 2, tabel 3 dan tabel 4 menunjukkan belum ada keseimbangan antara kinerja keuangan dengan non keuangan, antara kinerja aspek internal dan eksternal, maupun antara kinerja dari aspek proses dan orang. Rumah sakit saat ini berdasarkan balanced scorecard tidak adanya keseimbangan aspek karena cenderung berfokus pada aspek internal dan proses. (Tabel 1, tabel 2 dan tabel 3)

Tabel 2 Perbandingan aspek internal dan eksternal di IGD RSUD. Dr. M. Haulussy Ambon - Tahun 2017

\begin{tabular}{clcc}
\hline \multirow{2}{*}{ Internal } & Proses Bisnis & $60,7 \%$ & \\
& Internal & $730,7 \%$ \\
& $\begin{array}{l}\text { Pembelajaran \& } \\
\text { Pertumbuhan }\end{array}$ & 70 & \\
\hline \multirow{2}{*}{ Eksternal } & Keuangan & $25 \%$ & $87,5 \%$ \\
& Pelanggan & $62,5 \%$ &
\end{tabular}




\begin{tabular}{|c|c|c|c|c|}
\hline abel 3 & $\begin{array}{l}\text { Perbandingan aspek pr } \\
\text { IGD RSUD. Dr. M. Hc } \\
\text { Tahun } 2017\end{array}$ & $\begin{array}{l}\text { An or } \\
\text { Amb }\end{array}$ & & $\begin{array}{lll}\text { untuk tingkat } & \text { pertumbuhan } & \text { kunjungan } \\
\text { pelanggan untuk } & \text { tahun 2016/2015 sebesar }\end{array}$ \\
\hline Orang & $\begin{array}{l}\text { Pembelajaran } \\
\text { \&Pertumbuhan } \\
\text { Pelanggan }\end{array}$ & $\begin{array}{r}70 \% \\
62,5 \%\end{array}$ & $132,5 \%$ & $\begin{array}{l}3,48 \% \text { sedangkan target } \mathrm{RS} 5 \% \text { untuk itu } \\
\text { ukuran indikator ini mendapatkan nilai D }\end{array}$ \\
\hline Proses & $\begin{array}{l}\text { Keuangan } \\
\text { Proses Bisnis } \\
\text { Internal }\end{array}$ & $\begin{array}{c}25 \% \\
60,7 \%\end{array}$ & $85,7 \%$ & $\begin{array}{l}\text { dengan skor } 1 . \\
\text { Menurut Nuoraha nelanogan vano }\end{array}$ \\
\hline
\end{tabular}

Tabel 4. Perbandingan aspek keuangan dan non keuangan di IGD RSUD. Dr. M. Haulussy Ambon - Tahun 2017

\begin{tabular}{clc}
\hline & Proses Bisnis & \\
Non & Internal & $60,7 \%$ \\
Keuangan & Pembelajaran \& & $70 \%$ \\
& pertumbuhan & $62,5 \%$ \\
& Pelanggan & \\
\hline
\end{tabular}

Keuangan Keuangan $25 \%$

\section{Pembahasan}

Penelitian ini menunjukkan bahwa kinerja instalasi gawat darurat RSUD Dr. M. Haulussy Ambon berdasarkan balanced scorecard berada pada kisaran $58,2 \%$, yang termasuk dalam kondisi kurang sehat dengan kategori BBB, dengan persentase untuk masing-masing perspektif adalah: $62,5 \%$ untuk perspektif pelanggan, $25 \%$ untuk perspektif keuangan, sedangkan perspektif proses bisnis internal mencapai $60,7 \%$, serta perspektif pembelajaran dan pertumbuhan mendapat $70 \%$.

Pada perspektif pelanggan dalam penelitian ini, memperlihatkan ukuran indikator kepuasan pelanggan mencapai $71,86 \%$, untuk itu mendapatkan nilai B dengan skor 3, dari hasil analisis aspek dalam ukuran indikator ini, aspek kemudahan mencapai IGD memperoleh persentase tertinggi yaitu $77,26 \%$ dan aspek waktu tunggu rawat inap memiliki tingkat kepuasan terendah yaitu $62,44 \%$. Sedangkan puas akan tetap menggunakan pelayanan yang membuat mereka puas, dan sebaliknya pelanggan yang tidak puas, tidak akan kembali untuk menggunakan pelayanan yang membuat $193,2 \%$ mereka tidak puas. Hal tersebut sejalan dengan pernyataan dari Kartajaya, yang menyebutkan

$25 \%$ bahwa dalam rangka meningkatkan kunjungan pelanggan, kepuasan pasien perlu ditingkatkan, apabila kepuasan pasien meningkat maka loyalitas pasien akan terbentuk. Sedangkan menurut kutipan Anis, menyatakan bahwa untuk menunjukkan jumlah retensi konsumen otomatis akan meningkatkan jumlah konsumen yang dimiliki oleh suatu organisasi, dan bila rumah sakit telah memenuhi harapan pelanggan, maka rumah sakit tersebut tergolong berkualitas. ${ }^{2,10,11,12}$

Perspektif keuangan pada penelitian ini, menunjukkan pencapaian hasil yang paling terendah, dari empat ukuran indikator hanya terdapat dua indikator yang dapat dinilai, yaitu: tingkat pertumbuhan pendapatan IGD dan perbandingan realisasi dengan rencana pendapatan IGD, kedua ukuran indikator tersebut hanya memperoleh nilai $\mathrm{C}$ dengan skor 2, karena tidak mencapai target yang telah ditetapkan rumah sakit.

Hasil penelitian ini sesuai dengan yang dilakukan oleh Griffith et al, yang mengatakan http://ojs3.unpatti.ac.id/index.php/moluccamed 
bahwa cash flow margin atau margin arus kas dapat dilihat dari arus kas operasional dibagi dengan jumlah pendapatan organisasi, hal ini digunakan sebagai salah satu indikator kinerja utama balanced scorecard karena menunjukkan efisiensi organisasi dalam mengubah jumlah pendapatan dari pelayanan jasa yang dilakukan menjadi kas dan mengukur pemasukan organisasi. Hal ini sejalan dengan penelitian yang dilakukan oleh Rauscher, yang mengemukan bahwa kebijakan pendapatan yang meliputi ekstensifikasi dan intensifikasi peningkatan pendapatan rumah sakit. Ekstensifikasi peningkatan pendapatan rumah sakit dengan meningkatkan jumlah kunjungan pasien ke rumah sakit sehingga berdampak pada peningkatan pendapatan. Sedangkan dari hasil penelitian Wicaksono \& Bambang, yang mengungkapkan bahwa rumah sakit dapat melakukan peningkatan efisiensi sumber daya yang ada dalam rumah sakit dengan meningkatkan kemampuan menggali pendapatan fungsional dari jasa layanan kesehatan, keseimbangan kontribusi pendapatan fungsional rumah sakit terhadap belanja operasional pelayanan, serta peningkatan profitabilitas. ${ }^{4,13,14}$

Kinerja proses bisnis internal merupakan gambaran kinerja proses pelayanan di instalasi gawat darurat RSUD Dr. M. Haulussy Ambon.

Dari hasil analisis skoring berdasarkan kerangka balanced scorecard kinerja proses bisnis internal yang memiliki tujuh ukuran indikator, dengan hasil skoring: tiga diantaranya memperoleh nilai A dengan skor 4 yaitu ukuran indikator untuk jam buka pelayanan gawat darurat, ketersediaan tim penanggulangan bencana dan tidak adanya keharusan untk membayar uang muka, yang memperoleh nilai $\mathrm{C}$ dengan skor 2 yaitu ukuran indikator pemberi pelayanan kegawatdaruuratan yang bersertifikat, sedangkan untuk ukuran indikator kematian pasien di IGD dan tidak adanya keharusan untuk membayar uang muka mendapatkan nilai D dengan skor 1. Dan untuk ukuran indikator kemampuan menangani life saving anak dan dewasa tidak dapat diskoring sehingga mendapatkan skor 0 .

Menurut penelitian Holder dalam Djemari, yang mangatakan bahwa pertolongan kepada pasien gawat darurat dilakukan terlebih dahulu dengan melakukan survei primer untuk mengidentifikasi masalah-masalah yang mengancam hidup pasien, barulah selanjutnya dilakukan survei sekunder. Sejalan dengan penelitian Iqbal dalam Djemari, mengatakan bahwa primary survey harus dilakukan dalam waktu tidak lebih dari 2-5 menit, dengan penanganan yang simultan terhadap trauma dapat terjadi bila terdapat lebih dari satu keadaan yang mengancam jiwa. Sedangkan menurut Flynn dalam Djemari, menyatakan bahwa kegiatan yang menjadi tanggung jawab IGD banyak macamnya, secara umum dapat dibedakan menjadi tiga kegiatan, yaitu; 1) menyelenggarakan pelayanan gawat darurat, yang sebenarnya bertujuan untuk menyelamatkan kehidupan penderita (life saving), 2) menyelenggarakan pelayanan http://ojs3.unpatti.ac.id/index.php/moluccamed 
penaringan untuk kasus yang membutuhkan pelayanan warat inap intensif, 3) menyelenggarakan prlayanan informasi medis darurat. ${ }^{15}$

Hal ini sesuai dengan yang tercantum dalam Keputusan Menteri Kesehatan RI Nomor : 129/Menkes/II/2008, tentang standar pelayanan minimum RS, menyatakan bahwa yang termasuk tenaga kompeten bagi dokter atau perawat yang bertugas di IGD adalah mereka yang sudah memiliki sertifikat pelatihan BLS (Basic Life Support), atau PPGD (Pertolongan Pertama Gawat Darurat), atau GELS (General Emergency Life Support) atau ALS (Advanced Life Support) atau pelatihan sejenisnya. Menurut Yahya dalam Ismunandar, di setiap kejadian bencana, institusi kesehatan terutama rumah sakit selalu memegang peran yang sangat penting. Basoeki dkk dalam Ismunandar, mengemukakan bahwa RS khususnya IGD mempunyai tujuan agar tercapai pelayanan kesehatan yang optimal pada pasien secara cepat dan tepat serta terpadu dengan respon time selama 5 menit. $^{16}$

Menurut Gaspersz dalam penelitian Kawiana, menyebutkan bahwa dalam pengukuran kinerja pembelajaran dan pertumbuhan merupakan gambaran atas kemampuan rumah sakit dalam mengelola sumber daya manusia. Tujuan-tujuan dalam perspektif pembelajaran dan pertumbuhan merupakan pengendali untuk mencapai keunggulan outcome dalam ketiga perspektif keuangan, pelanggan dan proses bisnis internal. ${ }^{17}$
Pada perspektif pembelajaran dan pertumbuhan dalam penelitian ini, memperlihatkan ukuran indikator yang terendah yaitu produktivitas pegawai maupun akses pelatihan dan pendidikan mencapai nilai C dengan skor 2, yang tertinggi ukuran indikator tingkat absensi pegawai dengan nilai A dengan skor 4, sedangkan tingkat kepuasan pegawai dan retensi pegawai yang mencapai nilai B dengan skor 3 .

Sesuai dengan hasil penelitian tersebut, adapun pernyataan dari Handoko dalam penelitian Kholifah, bahwa kompensasi perlu ditingkatkan karena dapat meningkatkan motivasi dan kepuasan kerja sehingga mutu pelayanan juga meningkat. Pernyataan ini sejalan dengan penelitian dari Handaru, yang menyatakan bahwa kompensasi merupakan suatu bentuk penghargaan. Dari penelitian Nitisemito, yang menyebutkan bahwa lingkungan kerja yaitu keadaan atau sesuatu yang berada disekitar karyawan dan yang nantinya akan mempengaruhi karyawan tersebut dalam menjalankan sebuah tugas yang diberikan. Hal tersebut sejalan dengan pernyataan dari Muceke \& Jane, bahwa karyawan akan merasa lebih puas dan komit terhadap perusahaan dan apabila ia mempunyai pengalaman positif dari lingkungan kerja, karyawan tersebut akan lebih lama bertahan di perusahaan tersebut. Adapun hasil penelitian dari Putra \& Rahyuda, yang menyebutkan bahwa terdapat tiga faktor yang mampu mempengaruhi retensi karyawan, yaitu 
kompensasi, lingkungan kerja dan perceived organizational support. ${ }^{18,19,20,21,22}$

\section{Kesimpulan}

Kinerja instalasi gawat darurat dari perspektif pelanggan berada dalam kondisi kurang sehat, dari perspektif keuangan dalam kondisi tidak sehat, untuk perspektif proses bisnis internal berada dalam kondisi kurang sehat, serta dari perspektif pembelajaran dan pertumbuhan dalam kondisi sangat sehat. Sedangkan kinerja instalasi gawat darurat secara keseluruhan berada dalam kondisi kurang sehat dan belum adanya keseimbangan baik antar perspektif maupun antar aspek-aspek keseimbangan (internal-eksternal, proses-orang dan keuangan-non keuangan). Disarankan kepada pihak RSUD Dr. M. Haulussy Ambon untuk tingkatkan kepercayaan masyarakat terhadap pelayanan rumah sakit, peningkatan pemutakhiran data keuangan yang lebih bersifat micro atau satuan unit kerja, optimalisasi pelayanan yang sesuai dengan standar pelayanan minimum serta tingkatkan komitmen dan pengembangan kemampuan sumber daya manusia di instalasi gawat darurat.

\section{Referensi}

1. Mahmudi. Manajemen Kinerja Sektor Publik. Ed 3. Yogyakarta: Unit penerbit dan percetakan STIM YKPN. 2015

2. Nugraha F. Analisis kinerja Unit Gawat Darurat Kesehatan St. Carous dengan pendekatan Balanced Scorecard. Jakarta: kajian Administrasi Rumah Sakit, FKM - UI. 2012
3. Permana H. Diamond Head Drill \& Kepemimpinan dalam manajemen Rumah Sakit, Yogyakarta. Penerbit Andi. 2005

4. Griffith et al. Measuring Comparative Hospital Perfomance, Journal of Healthcare Management, 47(1): 41-57. 2000

5. Standar Pelayanan Minimal RSUD Dr. M. Haulussy Ambon, data dibagian pelayanan medik, tidak dipublikasikan.

6. Rencana Strategis (Renstra) 2014-2019 RSUD Dr. M. Haulussy Ambon (2014), data di bagian perencanaan, tidak dipublikasikan. 2012

7. Kaplan R. S, Norton P.D. Balanced Scorecard; menerapkan strategi Menjadi Aksi, Erlangga, Jakarta. 2000

8. Rangkuti. SWOT Balanced Scorecard, cetakan kedelapan, Jakarta : PT Gramedia Pustaka Utama. 2015

9. Sugiyono. Metode Penelitian Kombinasi (Mixed Methods), Bandung: CV Alfabeta. 2015

10. Kartajaya H. Hermawan Kartajaya on Service. Bandung : Mizan. 2006

11. Anis. Employee retention relationship to training and development: A compensation perspective. African Journal of Business Management. 2011. 5(7): 2679-2685.

12. Supranto. Pengukuran Tingkat Kepuasan Pelanggan untuk Menaikkan Pangsa Pasar, Penerbit Rineka Cipta. 2001. Jakarta, 230-243.

13. Rauscher M. Tax Competition, Capital Mobility and Innovation in the public sector. German Economic Review 8. 2007. pp 28-40.

14. Wicaksono. \& Bambang. Balanced Scorecard pada Rumah Sakit Umum Daerah (RSUD) Blambangan Kabupaten Banyuwangi. Universitas Tarumanegara Banyuwangi. Vol. 9. No. 26. 2012. ISSN: 1693-4083.

15. Djemari. Pelayanan Gawat Darurat (Emergency Care). 2011

16. Ismunandar. Kesiapan Rumah Sakit Umum Daerah Palu dalam penanganan korban bencana. Jurnal Keperawatan Soedirman (The Soedirman Journal of Nursing), Vol 8, No. 3. 2013 
17. Kawiana I. M. Analisis Kinerja berdasarkan Balanced Scorecard Unit Rawat Jalan Poliklinik RSU Surya Husadha Denpasar di tahun 2012, Tesis tidak dipublikasikan, Depok: Program studi Kajian Administrasi Rumah Sakit, FKM - UI. 2012.

18. Kholifah. Analisis kinerja dengan perspektif BSC di RSUD. Aji Batara Agung Dewa Sakti Samboja, Tesis tidak dipublikasikan, Makassar: FKM Unhas. 2015

19. Handaru. Pengaruh Lingkungan Kerja, Kompensasi dan Komitmen Organisasi Terhadap Kepuasan Kerja Karyawan Di RS. X, Jurnal Riset Manajemen Sains Indonesia. 2013. 4(1): 117-135.
20. Nitisemito. Manajemen Personalia, Manajemen Sumber Daya Manusia, Edisi Ketiga,Cetakan Kesembilan, 2006. Yogyakarta: Ghalia Indonesia

21. Muceke \& Jane. Influence of Leadership Style on Academic Staff Retention in Public Universities in Kenya, International Journal of Business and Social Science, 2012. 3(21):297-302.

22. 22. Putra I.B.G.S \& Rahyuda A.G. Pengaruh kompensasi, lingkungan kerja dan perceived organizational support (POS) terhadap retensi karyawan, Fakultas Ekonomi \& Bisnis, Universitas Udayana: Bali, EJurnal Manajemen Unud, Vol. 5, No. 2, 2016. ISSN: $2302-89$ 